\title{
CARACTERIZAÇÃO E AVALIAÇÃO DA QUALIDADE DE SOPAS DESIDRATADAS ELABORADAS COM FARINHA DE BATATA DURANTE O TEMPO DE ARMAZENAMENTO
}

\author{
ALEXANDRA PEREIRA DOS SANTOS* \\ TIYOKO NAIR HOJO REBOUÇAS** \\ JOEL CAMILO CARNEIRO DE SOUZA*** \\ RENATA CRISTINAFERREIRA BONOMO**** \\ LARISSA MATOS DA SILVA*****
}

\begin{abstract}
Sopas formuladas com 100:0, 80:20, 60:40, 40:60, 20:80 e 0:100\% proporções de farinha de batata em substituição ao amido de milho foram avaliadas por meio de análises físico-quimicas e funcionais durante 90 dias de armazenamento. A cada 15 dias avaliaram-se os teores de sólidos solúveis totais, $\mathrm{pH}$, acidez total titulável, umidade, cor $\left(\mathrm{L}^{*}, \mathrm{a}^{\star} \mathrm{e} \mathrm{b}^{\star}\right)$, índice de solubilidade em água, índice de absorção em água e viscosidade. A incorporação de farinhas de batata nas formulações proporcionou aumento nos teores de proteínas, fibras e cinzas, e diminuição do valor calórico e conteúdo de carboidratos. As sopas desidratadas sofreram pequenas variações nas características físico-químicas durante o tempo total de armazenamento, com exceção da viscosidade que revelou redução acentuada, sendo maior nas formulações contendo 40, 60, 80 e 100\% de farinha de batata.
\end{abstract}

PALAVRAS-CHAVE: VIDA-DE-PRATELEIRA; SOPA; Solanum tuberosum L.; PROPRIEDADES FUNCIONAIS.

* Engenheira Agrônoma, Mestre em Engenharia de Alimentos, Universidade Estadual do Sudoeste da Bahia (UESB), Itapetinga, BA (e-mail:alepersant@yahoo.com.br).

** Engenheira Agrônoma, Doutora em Produção Vegetal, Professora, UESB, Itapetinga, BA (e-mail: tiyoko@uesb.br).

*** Engenheiro de Alimentos, Doutor em Ciência e Tecnologia de Alimentos, Professor, Universidade Federal do Espírito Santo (UFES), Alegre, ES (e-mail: carneirojoel@hotmail.com).

**** Engenheira de Alimentos, Doutora em Ciência e Tecnologia de Alimentos, Professora, UESB, Itapetinga, BA (e-mail: bonomorcf@yahoo.com.br).


larimatos_eng@hotmail.com). 


\section{INTRODUÇÃO}

As hortaliças, consideradas ingredientes naturais e nutritivos, têm baixo teor de gordura e podem ser adicionadas em muitos produtos, atuando também como aromatizantes e corantes. Quando desidratadas mantém seu sabor inalterado por longos períodos, pois a redução da atividade de água diminui a taxa de desenvolvimento de microorganismos no produto (CRUZ, 1990, DIONELLO et. al., 2009).

A farinha de batata pode ser definida como o produto obtido da moagem de fatias de batata desidratadas (WILLARD, 1975). Segundo SABLANI e MUJUMDAR (2006) apresenta, aproximadamente, $7,6 \%$ de água, $79 \%$ de carboidratos, $17,5 \%$ de amido, $8,0 \%$ de proteínas, $0,8 \%$ de lipídios, além de cálcio, ferro, potássio e vitamina $\mathrm{C}$.

Dentre as vantagens da utilização da farinha de batata para a elaboração de sopas desidratadas destacam-se suas características nutricionais, sensoriais e alta reserva energética, principalmente pelo conteúdo de amido. Segundo FRANCO et al. (2002), o amido da batata apresenta baixa temperatura de formação de pastas proporcionando a consistência cremosa procurada em sopas e menor tempo de cozimento do produto. Além disso, o uso de matérias-primas tradicionais para o desenvolvimento de farinhas que apresentem melhores propriedades funcionais para serem aplicadas em produtos e formulações contribui para a diversificação do uso da batata, servindo de incentivo às regiões produtoras.

As sopas desidratadas facilitam a vida do consumidor, principalmente para as pessoas que dispõem de pouco tempo para a preparação de alimentos, pois requerem apenas a adição de água e aquecimento. Podem ser definidas como o produto obtido pela mistura de ingredientes, como cereais e vegetais desidratados, farinha de cereais, leite em pó, condimentos, massas alimentícias, extrato de carne e outros aprovados pela legislação. Podem ainda ser enriquecidas com levedura inativa, concentrado de caroteno e fosfato de cálcio, mas não é tolerada a adição de conservadores e corantes (BRASIL, 1978).

De acordo com SARANTÓPOULPS, OLIVEIRA e CANAVESI (2001), a sopa desidratada resulta da mistura de ingredientes que requerem grande proteção contra oxigênio e a umidade, assim como contra a perda de componentes aromáticos.

A determinação da vida-de-prateira pode ser definida como o período de tempo decorrido entre a produção e o consumo do alimento, durante o qual se mantém a aceitabilidade do produto pelos consumidores e nível satisfatório de qualidade. Essa qualidade pode ser avaliada por parâmetros sensoriais (sabor, odor, cor e textura), características gerais de aparência, carga microbiana, absorção de componentes da embalagem ou valor nutricional (SARANTÓPOULPS, OLIVEIRA e CANAVESI, 2001; SILVIERE e OLIVEIRA, 2002).

Sob o ponto de vista da vida-de-prateleira, a qualidade dos alimentos é definida por parâmetros fisiológicos, valores nutricionais e atributos sensoriais (como cor, sabor e textura). A diminuição da qualidade e a redução da vida-de-prateleira podem ser consequência do efeito de uma ou mais dessas propriedades (PFIFFER et al.; 1999 citado por SILVIERE e OLIVEIRA; 2002).

A vida útil de vegetais desidratados e transformados em farinha ou pó costuma ser menor do que a dos vegetais apenas desidratados (CRUZ, 1990). Os principais fatores de deterioração de vegetais desidratados são as reações de escurecimento não enzimático, o ganho de umidade, a oxidação de pigmentos (como clorofila e carotenóides) e as reações de oxidação de lipídios e de vitaminas ( $A, B_{1}$, C) (SARANTÓPOULPS, OLIVEIRA e CANAVESI, 2001):

No presente estudo objetivou-se caracterizar por meio de análises físico-quimicas e funcionais sopas desidratadas formuladas com 100:0, 80:20, 60:40, 40:60, 20:80 e 0:100\% proporções de farinha de batata em substituição ao amido de milho, acompanhando-se sua vida-de-prateleira durante 90 dias de armazenamento.

\section{MATERIAL E MÉTODOS}

O experimento foi conduzido nos Laboratórios de Tecnologia de Produtos de Origem Vegetal e Engenharia de Processos, pertencentes ao Departamento de Tecnologia Rural e Animal da Universidade Estadual do Sudoeste da Bahia, Campus Juvino Oliveira, Itapetinga, Bahia. 


\subsection{MATÉRIA-PRIMA}

As sopas foram elaboradas com farinha de batata processada com a cultivar Markies e secas a temperatura de $60^{\circ} \mathrm{C}$, leite em pó integral, amido de milho, sal e as seguintes especiarias desidratadas: coentro (Coriandrum sativum L.), salsa (Petroselium sativum L.), pimenta do reino (Piper nigrum L.), manjericão (Ocimum basilicum L.), alho (Allium sativum L.) e cebola (Allium cepa L.). Os ingredientes foram adquiridos no mercado das cidades de Itapetinga e Vitória da Conquista.

\subsection{OBTENÇÃO DAFARINHA DE BATATA}

As batatas foram lavadas, descascadas e imersas em solução de bissulfito de sódio a 200 ppm. Realizou-se o corte em fatias de 1,2 $\mathrm{mm}$ por meio de fatiador de legumes. As fatias, branqueadas por seis minutos, foram submetidas ao processo de secagem na temperatura de $60^{\circ} \mathrm{Ce}$ velocidade do ar de $1,5 \mathrm{~m} \cdot \mathrm{s}^{-1}$ até a umidade final de $8 \%$ b.u., em secador de bandejas Poly-Dry ${ }^{\circledR}$, modelo PD-150. Triturou-se o material desidratado e as farinhas obtidas foram acondicionadas em embalagem de polietileno e armazenadas à temperatura ambiente.

\subsection{ELABORAÇÃO DAS SOPAS}

Todos os ingredientes foram pesados, segundo as suas proporções (Tabela 1), homogeneizados, acondicionados em embalagem de polipropileno metalizado e armazenados à temperatura ambiente. Em cada embalagem foram colocadas aproximadamente 150 gramas de amostras. Para o preparo das sopas, 17,50 gramas do produto foram dissolvidos em $350 \mathrm{~mL}$ de água fria e cozidos em fogo lento por 20 minutos. As formulações das sopas desidratadas foram desenvolvidas segundo ensaios realizados previamente.

\section{TABELA 1 - FORMULAÇÃO DAS SOPAS DESIDRATADAS}

\begin{tabular}{lc}
\hline Ingredientes & Porcentagem (\%) \\
\hline Amido de milho + Farinha de Batata & 55 \\
Leite em pó integral & 20 \\
Especiarias desidratadas (coentro, cebola, alho, & 10 \\
pimenta do reino, manjericão e salsa) & 15 \\
Sal & \\
\hline
\end{tabular}

\subsection{COMPOSIÇÃO CENTESIMAL, ANÁLISES FISICO-QUIMICAS E FUNCIONAIS}

As análises de umidade, cinza, proteína e lipídios das amostras foram realizadas segundo a metodologia descrita pela AOAC (1996), sendo os carboidratos totais calculados por diferença e o valor calórico pelos fatores de conversão de Atwater: $4 \mathrm{kcal} / \mathrm{g}$ para proteína, $4 \mathrm{kcal} / \mathrm{g}$ para carboidratos e $9 \mathrm{kcal} / \mathrm{g}$ para lipídios, de acordo com a equação: $\mathrm{VC}=(\%$ proteína $\times 4,0)+(\%$ extrato etéreo $\times 9,0)$ + (\% carboidratos $\times 4,0)$, conforme OSBORNE e VOOGT (1978).

Os sólidos solúveis totais (SST), a acidez total titulável (ATT) e o pH das amostras foram analisados de acordo com o INSTITUTO ADOLFO LUTZ (2008). A atividade de água foi determinada a $25^{\circ} \mathrm{C}$ por leitura direta em instrumento Aqualab TE da Decagon Devices, conforme BRASEQ (2009).

Os índices de absorção e solubilidade em água foram determinados segundo metodologia descrita por ANDERSON, CONWAY e GRIFFIN (1969).

A determinação da viscosidade foi realizada de acordo com DELAHAYE (2001) com modificações. Usou-se Reômetro Brookfield, Modelo DVII, com spindle no 4, rotação de $60 \mathrm{rpm}$ e temperatura de $40^{\circ} \mathrm{C}$. As amostras foram preparadas dissolvendo-se $17,5 \mathrm{~g}$ da sopa desidratada em $350 \mathrm{~mL}$ de água à temperatura ambiente e cozidas em fogo baixo por 20 minutos.

A cor das sopas desidratadas foi avaliada em Colorímetro, modelo ColorQuest XE, sendo os 
resultados de três leitura em cada amostras expressos como $L^{*}, a^{*}$ e $b^{*}$. $O$ índice de escurecimento (IE) foi determinado por colorimetria $L^{*}, a^{*} e b^{*}$, mediante leitura em Colorímetro, Modelo ColorQuest XE, e calculado de acordo com PALOU et al. (1999) pela fórmula:

$$
I E=\left[\frac{100(X-0,31)}{0,172}\right] \quad \text { em que: } \quad X=\frac{(a+1,75 L)}{(5,645 L+a-3,021 b)}
$$

\subsection{DELINEAMENTO EXPERIMENTAL E ANÁLISE ESTATÍSTICA}

Adotou-se delineamento experimental inteiramente casualizado com três repetições. Os tratamentos consistiram na substituição do amido de milho pela farinha de batata na formulação das sopas desidratadas em porcentagem (0, 20, 40, 60, 80 e 100\%). Quando ocorreu efeito significativo entre os parâmetros utilizou-se a análise de regressão para descrever o comportamento das características avaliadas em função das porcentagens de farinha de batata em substituição ao amido de milho. Os modelos de regressão foram escolhidos com base na significância dos parâmetros. As análises estatísticas foram realizadas usandose o programa estatístico SAEG versão 9.0 (SAEG, 2005).

\section{RESULTADOS E DISCUSSÃO}

\subsection{CARACTERIZAÇÃO FÍSICO-QUÍMICA DA FARINHA DE BATATAE DO AMIDO DE MILHO}

De acordo com a Tabela 2, a farinha de batata apresentou maior teor de acidez, proteínas, cinzas, lipídios, fibra bruta e absorção em água que o amido de milho e menores valores de umidade, carboidratos e valor calórico. A farinha de batata apresenta vantagem em relação ao amido de milho devido maior capacidade de absorção de água, o que sugere o seu uso em formulações de produtos instantâneos.

\subsection{CARACTERIZAÇÃO FÍSICO-QUÍMICA DAS FORMULAÇÕES}

Observa-se na Tabela 3 que os valores de proteínas, cinzas, fibras bruta, índice de absorção em água, índice de escurecimento e as coordenadas $a^{*}$ e $b^{\star}$ aumentaram com o acréscimo de farinha de batata nas formulações. $\mathrm{O}$ índice de solubilidade em água, o pH, a luminosidade ( $\left.\mathrm{L}^{\star}\right)$ e os lipídios não sofreram influência da concentração das farinhas de batata $(p>0,05)$. Aumidade aumentou e depois decresceu. O valor calórico e o teor de carboidratos diminuíram com adição de farinha de batata nas formulações.

TABELA 2 - CARACTERIZAÇÃO FÍSICO-QUIMICA DA FARINHA DE BATATA E AMIDO DE MILHO

\begin{tabular}{|c|c|c|}
\hline Parâmetros & Farinha de Batata & $\begin{array}{c}\text { Amido de milho* } \\
\text { Maisena }{ }^{\circledR}\end{array}$ \\
\hline Umidade (\%) & 6,92 & 9,40 \\
\hline Acidez (\%) & 6,21 & 2,30 \\
\hline Proteínas (\%) & 6,45 & 0,30 \\
\hline Cinzas (\%) & 2,89 & 0,04 \\
\hline Lipídios (\%) & 0,89 & 0,00 \\
\hline Fibra Bruta (\%) & 3,32 & 2,02 \\
\hline Carboidratos (\%) & 79,54 & 88,20 \\
\hline Energia (kcal/100g) & 351,97 & 354,00 \\
\hline Absorção em água (\%) & 553,52 & 177,10 \\
\hline Solubilidade em água (\%) & 4,73 & 4,18 \\
\hline
\end{tabular}

* Fonte: RUIZ et al. (2003). 


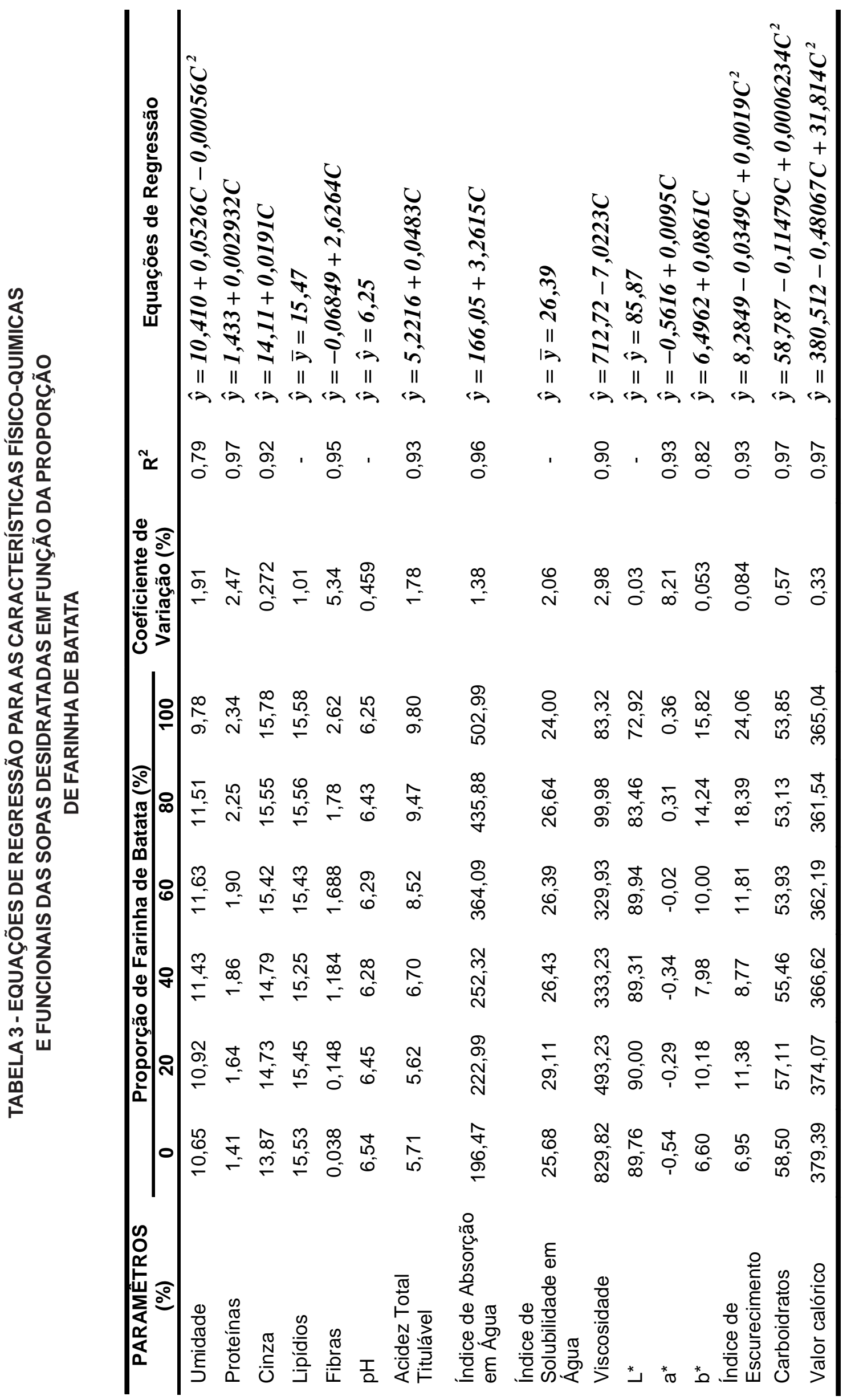


Os teores de proteínas, fibras e cinzas das sopas desidratadas aumentaram com o acréscimo de farinha de batata nas formulações (Tabela 3 ) em função dos maiores teores desses componentes na farinha de batata (Tabela 2), sendo o melhor ajuste obtido para os parâmetros com o modelo linear.

A quantidade de lipídios não foi influenciada pela quantidade de farinha de batata (média 15,47\%), provavelmente devido ao baixo teor de lipídios encontrados na farinha e no amido de milho. GARCIA et al. (2007) encontraram em sopas desidratadas elaboradas com farinhas de tubérculos de batata baroa, especiarias desidratadas e leite em pó integral valores de proteínas variando de 9,60 a 10,7\%, fibras de 8,29 a 8,35\%, cinzas de 6,22 a 6,77\% e lipídios de 9,65 a 10,68\%.

O valor calórico sofreu decréscimo com o aumento da quantidade de farinha de batata (Tabela 3 ) em razão do maior teor de carboidratos encontrados no amido de milho (Tabela 2). Os valores calóricos obtidos estão de acordo com a Tabela de Composição de Alimentos para sopas desidratadas, segundo o estudo nacional da despesa familiar (ENDEF) que é de $364 \mathrm{kcal}^{1} 100 \mathrm{~g}^{-1}$ (IBGE, 1999). O modelo quadrático foi o que melhor se ajustou aos dados com coeficiente de determinação de 0,97.

A quantidade de carboidratos diminuiu com o decréscimo do amido de milho nas formulações (Tabela 3), fato explicado pelo menor teor de carboidrato encontrado na farinha de batata.

A umidade aumentou com o acréscimo da farinha de batata nas formulações até $60 \%$, quando se observou decréscimo na umidade. Essa variação no teor de umidade decorre do fato das sopas desidratadas resultarem da mistura de vários ingredientes com diferentes umidades e atividades de água, além de distintas concentrações. A equação que melhor se ajustou aos dados foi a quadrática com coeficiente de determinação de 0,79 (Tabela 3).

Os valores de $\mathrm{pH}$ não foram influenciados pelo aumento no conteúdo de farinha de batata nas formulações (Tabela 3), ficando próximo dos teores encontrados na farinha de batata $(6,34)$.

A acidez total titulável (ATT) aumentou linearmente com o acréscimo de farinha de batata nas formulações, variando de 5,71 a 9,80\%. Esse fato pode ser explicado pelo maior teor de acidez total titulável encontrado na farinha de batata em relação ao amido de milho (Tabela 2).

Os índices de absorção em água (IAA) aumentaram com o incremento na concentração de farinha de batata, variando de 196,47 a 502,99\%. A farinha de batata apresenta IAA muito superior ao amido de milho (Tabela 2), sendo o aumento na porcentagem de absorção em água nas formulações da ordem de 2,56 vezes.

Os índices de solubilidade em água (ISA) não sofreram influência do aumento da proporção de farinha de batata nas formulações das sopas desidratadas (Tabela 3), apresentado valor médio de 26,39\%. Esse resultado pode ser explicado pelos índices de absorção em água semelhantes apresentados pela farinha de batata e pelo amido de milho (Tabela 2).

A viscosidade diminuiu com o decréscimo nos teores de amido nas formulações, variando de 83,32 a 829,82 cps, pois o amido de milho atua como espessante (principal componente responsável pela viscosidade). DELAHAYE (2001) encontrou valores de viscosidade variando de 620 a $675 \mathrm{cps}$ para sopas elaboradas com farinha de banana verde e vegetais desidratados.

O valor $L$ * não sofreu variação com o aumento da proporção de farinha de batata nas formulações, apresentando valor médio de 85,87 (Tabela 3).

O valor da coordenada de cromaticidade $a^{\star}$, que varia do vermelho (+a) ao verde (-a), aumentou com o acréscimo de farinha de batata nas formulações (variação de $-0,54$ a 0,36 ). As formulações com 0, 20, 40 e 60\% apresentaram coloração mais próxima do verde, enquanto as demais ficaram mais próximas do vermelho. A equação linear ajustou-se melhor aos dados com $\mathrm{R}^{2}$ de 0,93 (Tabela 3). As sopas desidratadas resultam da mistura de vários ingredientes que influenciam a coloração do produto.

O valor da coordenada $b^{\star}$, que indica tonalidades do amarelo (+b) ao azul (-b), mostrou comportamento semelhante ao valor $a^{\star}$, evidenciando tendência ao amarelo para todas as amostras analisadas e maior intensidade para a formulação com $100 \%$ de farinha de batata (Tabela 3).

As formulações com maiores concentrações de farinha de batata originaram produtos com coloração mais escura. O índice de escurecimento variou de 6,95 a 24,06 , sendo que a equação quadrática ajustou-se melhor aos dados experimentais com $R^{2}$ de 0,93 (Tabela 3). 


\subsection{EFEITO DO TEMPO DE ARMAZENAMENTO NAS PROPRIEDADES FÍSICO-QUÍMICAS E FUNCIONAIS DAS SOPAS DESIDRATADAS}

A Figura 1 evidencia variação nos teores de umidade de 4,20\%, 16,17\%, 12,94\%, 14,66\%, $14,17 \%$ e $10,42 \%$ para as sopas formuladas, respectivamente, com $0,20,40,60$, 80 e 100\% de farinha de batata após 90 dias de armazenamento. As sopas desidratadas necessitam de maior tempo para atingir a umidade de equilíbrio, devido à mistura de ingredientes com diferentes umidades.

$\mathrm{O}$ pH do produto apresentou pequenas variações ao longo do armazenamento (Figura 2), permanecendo próximo ao valor inicial e confirmando a eficiência da embalagem na sua conservação. A maior variação foi observada para a formulação que continha $80 \%$ de farinha de batata com redução de 2,64\% no valor de pH após 90 dias de armazenamento. A formulação sem adição de farinha de batata sofreu menor variação, com acréscimo de $0,1 \%$ no valor de $\mathrm{pH}$ no mesmo período.

A acidez das amostras sofreu pequenas variações ao longo do armazenamento (Figura 3). A formulação que continha $60 \%$ de farinha de batata apresentou a menor variação na acidez com aumento de $0,1 \%$. Já a maior variação foi observada na sopa desidratada que continha $40 \%$ de farinha de batata com aumento de 1 .

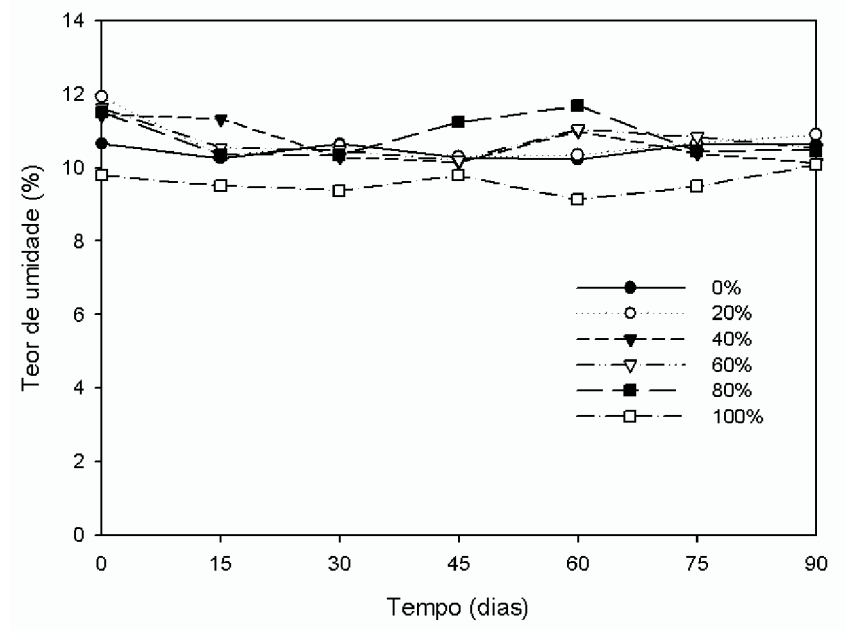

FIGURA 1 - VARIAÇÃO DO TEOR DE UMIDADE DAS SOPAS DESIDRATADAS EM FUNÇÃO DO TEMPO DE ARMAZENAMENTO



FIGURA 2 - VARIAÇÃO DO pH DAS SOPAS DESIDRATADAS EM FUNÇÃO DO TEMPO DE ARMAZENAMENTO 


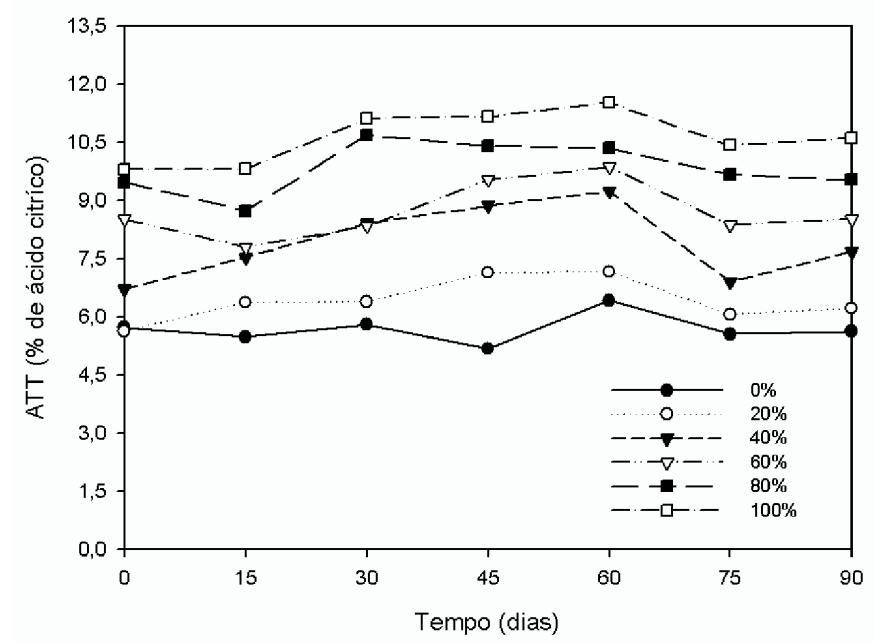

\section{FIGURA 3 - VARIAÇÃO DOS VALORES DE ATT DAS SOPAS DESIDRATADAS EM FUNÇÃO DO TEMPO DE ARMAZENAMENTO}

A variação do IAA aumentou com o acréscimo na proporção de farinha de batata nas formulações (Figura 4). Nas formulações contendo até $40 \%$ de farinha, o IAA permaneceu praticamente constante ao longo do armazenamento. As maiores variações ocorreram nas sopas desidratadas elaboradas com 60, 80 e 100\% de farinha de batata, com redução do IAA de 22,0, 17,72 e 12,73\%, respectivamente, após 90 dias. Esse fato pode ser devido à diminuição da uniformidade das partículas e decréscimo na quantidade de amido nas formulações, influenciando sua capacidade de absorção de água.

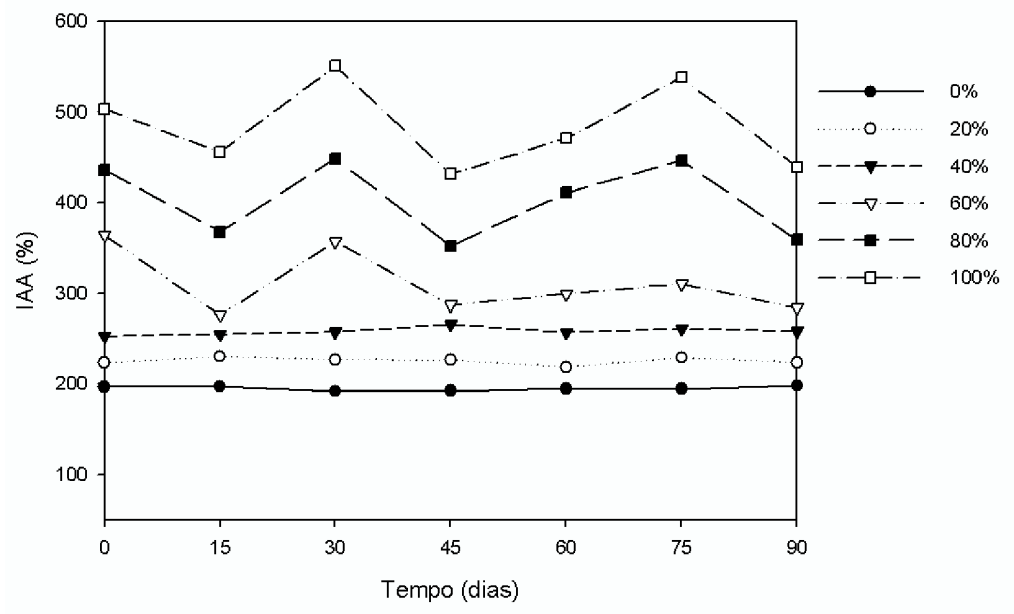

\section{FIGURA 4 - VARIAÇÃO DO ÍNDICE DE ABSORÇÃO EM ÁGUA DAS SOPAS DESIDRATADAS EM FUNÇÃO DO TEMPO DE ARMAZENAMENTO}

O ISA apresentou menor variação nas formulações com $80 \%$ de farinha de batata, verificando-se redução de 2,0\% após 90 dias de armazenamento. A maior variação ocorreu com as formulações com $100 \%$, constatando-se aumento de $27 \%$ do ISA após 90 dias de armazenamento. Para todas as formulações houve aumento do ISA com o tempo de armazenamento, exceto para as sopas desidratadas com 20 e $80 \%$ de farinha de batata (Figura 5). 


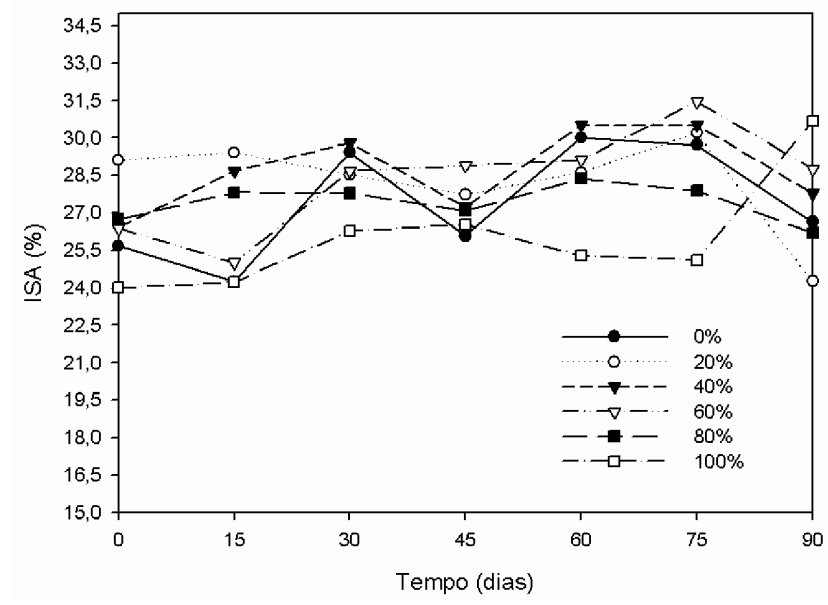

\section{FIGURA 5 - VARIAÇÃO DO ÍNDICE DE SOLUBILIDADE EM ÁGUA DAS SOPAS DESIDRATADAS EM FUNÇÃO DO TEMPO DE ARMAZENAMENTO}

A viscosidade do produto diminuiu com o tempo de armazenagem, resultado semelhante ao encontrado por GARCIA et al. (2007) que observaram decréscimo na viscosidade em sopas elaboradas com farinhas de batata baroa a partir dos 45 dias de armazenamento. As formulações com menores proporções de farinha de batata apresentaram maior estabilidade com o armazenagem. A redução mais acentuada foi verificada nas formulações contendo 40, 60, 80 e 100\% (60, 57, 66 e 76\% respectivamente) após os 90 dias de armazenamento (Figura 6).

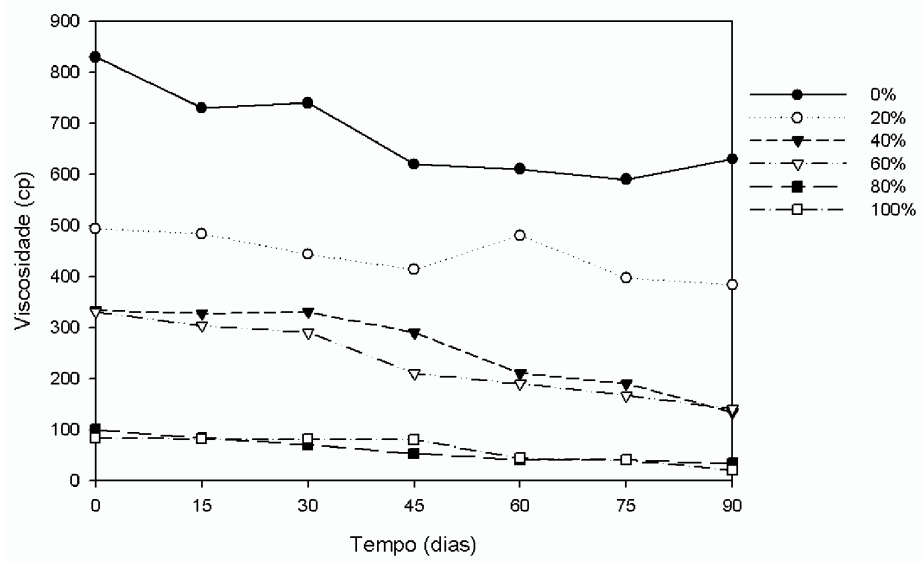

\section{FIGURA 6 - VARIAÇÃO DA VISCOSIDADE DAS SOPAS DESIDRATADAS EM FUNÇÃO DO TEMPO DE ARMAZENAMENTO}

Observou-se (Figura 7) pequena variação nos valores de $L^{*}$, demonstrando que a luminosidade do produto se manteve ao longo do tempo de armazenamento. A maior variação foi verificada para a formulação contendo apenas farinha de batata, com aumento de $2,71 \%$ no valor de L* após 90 dias.

As coordenadas $a^{*}$ e $b^{*}$ também sofreram pequenas variações ao longo do tempo de armazenamento. Para a coordenada $\mathrm{a}^{\star}$, a maior variação foi observada para as formulações contendo 60,80 e 100\% de farinha de batata (Figura 8). Para a coordenada b*, as formulações com 0, 20 e $40 \%$ de farinha de batata apresentaram maior variação (Figura 9). De acordo com CRUZ (1990) e SARANTÓPOULPS, OLIVEIRA e CANAVESI (2001), os vegetais desidratados e transformados em farinhas ou pós são mais sujeitos a perda da cor durante a estocagem. 


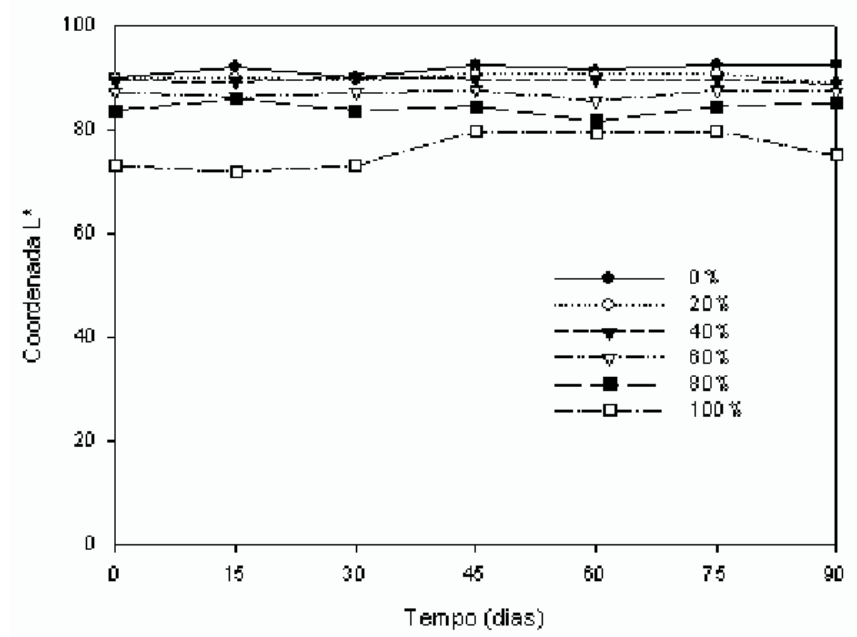

FIGURA 7 - VARIAÇÃO DA COORDENADA L* DAS SOPAS DESIDRATADAS EM FUNÇÃO DO TEMPO DE ARMAZENAMENTO

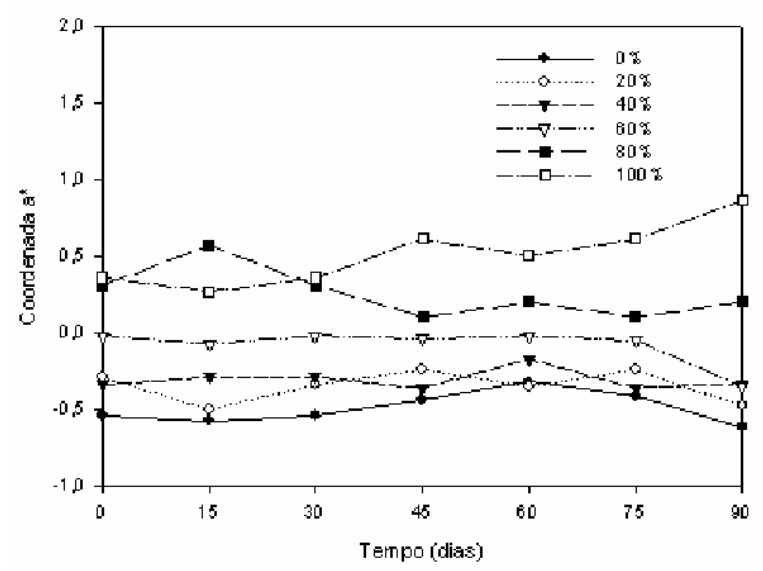

FIGURA 8 - VARIAÇÃO DA COORDENADA a* DAS SOPAS DESIDRATADAS EM FUNÇÃO DO TEMPO DE ARMAZENAMENTO

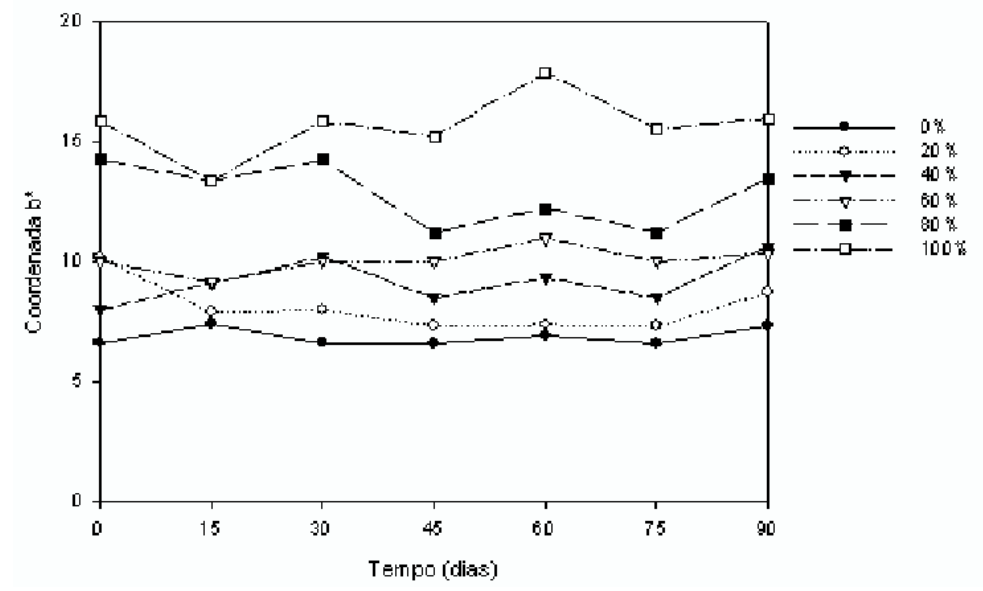

FIGURA 9 - VARIAÇÃO DA COORDENADA b* DAS SOPAS DESIDRATADAS EM FUNÇÃO DO TEMPO DE ARMAZENAMENTO 
A variação do índice de escurecimento foi maior conforme se aumentou a proporção de farinha de batata nas formulações (Figura 10). Para as sopas sem farinha de batata, os índices de escurecimento permaneceram praticamente constantes ao longo da armazenagem. As maiores variações foram observadas para as sopas contendo 80 e $100 \%$ de farinha de batata.

A cor, fator inicial levado em consideração pelo consumidor ao escolher um alimento, constitui uma de suas mais importantes características (REIS, 2007). Segundo SARANTÓPOULPS, OLIVEIRA e CANAVESI (2001) a reação de Maillard, também chamada de escurecimento não enzimático, representa importante fator de deterioração dos alimentos durante a estocagem, principalmente em elevadas temperaturas de comercialização. Tal reação ocorre entre aminoácidos e açúcares redutores e resulta na formação de melanoidinas, que são polímeros nitrogenados de coloração escura. Além da formação de cor indesejável em alimentos proteicos, podem provocar perda da qualidade nutricional e proporcionar modificações no sabor.

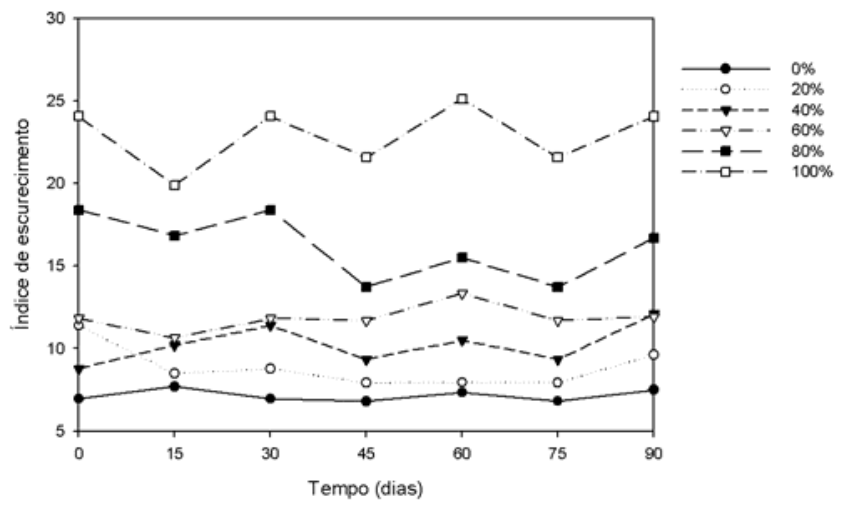

\section{FIGURA 10 - ÍNDICE DE ESCURECIMENTO DAS SOPAS DESIDRATADAS EM FUNÇÃO DO TEMPO DE ARMAZENAMENTO}

\section{CONCLUSÃo}

A incorporação de farinha de batata nas formulações das sopas desidratadas proporcionou aumento nos teores de proteínas, fibras e cinzas, e diminuição do valor calórico e conteúdo de carboidratos do produto.

As sopas desidratadas sofreram pequenas variações nas características físico-químicas durante o tempo total de 90 dias de armazenamento, demonstrando boa estabilidade e a eficiência da embalagem na sua conservação.

Houve redução da viscosidade das sopas desidratadas com o tempo de armazenamento, sendo mais acentuada nas formulações contendo 40, 60, 80 e 100\% de farinha de batata, que demonstra menor estabilidade do gel com o aumento da quantidade dessa farinha.

\section{ABSTRACT \\ CHARACTERIZATION AND EVALUATION OF QUALITY OF SOUPS DEHYDRATED PRODUCED WITH FLOUR OF POTATOES DURING TIME OF STORAGE}

The soups made with 100:0, 80:20, 60:40, 40:60, 20:80 and 0:100\% proportion of potato flour in place of maize starch were evaluated by means of physico-chemical and functional analysis over 90 days of storage. Every 15 days it was evaluated the levels of soluble solids, $\mathrm{pH}$, titratable acidity, moisture, color $\left(L^{*}, a^{*} b^{*}\right)$, rate of water solubility, rate of absorption in water and viscosity. The addition of potato flour in the formulations increased the levels of protein, fiber and ash, and provided a reduction of calorie and carbohydrate content. The dehydrated soups had small variations in physicochemical characteristics during the total time of storage, except for the viscosity was reduced sharply, being higher in formulations containing 40,60, 80 and $100 \%$ of potato flour.

KEY-WORDS: SHELF-LIFE; SOUP; Solanum Tuberosum L.; FUNCTIONAL PROPERTIES. 


\section{REFERÊNCIAS}

1 ANDERSON, R. A.; CONWAY, V. F. P.; GRIFFIN, E. L. Gelatiniozation of corn grits by roll-and extrusion-cooking. Cereal Science Today, v. 14, n. 1, p4-7, 1969.

2 AOAC. Association of Official Analytical Chemists. Official methods of analysis of AOAC International. $16^{\text {th }}$ ed. Gaithersburg, 1996.1141 p.

3 BRASEQ. Brasileira de Equipamentos Ltda. Boletim Técnico Informativo Braseq. Jarinu (SP), 2009.10 p.

4 BRASIL. Ministério da Saúde. Agência Nacional de Vigilância Sanitária. Resolução - RDC nº 12 de 24 de agosto de 1978. Padrões de identidade e qualidade para alimentos e bebidas. Diário Oficial [da] Republica Federativa do Brasil, Brasília, 1978. Disponível em: http://www.anvisa.gov.br/legis/resol/12_78_sopa.htm. Acesso em: 29 de agosto de 2008.

5 CRUZ, G.A. Desidratação de alimentos. São Paulo: Globo Rural, 1990. 207 p.

6 DELAHAYE, E.P. de. Evaluacion nutricional de sopas deshidratadas a base de harina de plantano verde. Digetibilidad in vitro del almidon. Acta Cientifica Venezolana, Venezuela, v. 52, p. 278-282, 2001.

7 DIONELLO, R.G.; BERBERT, P. A.; MOLINA, M. A.B.; PEREIRA, R.C.; VIANA, A. P.; CARLESSO, V. O. Secagem de fatias de abacaxi in natura e pré-desidratadas por imersão-impregnação: cinética e avaliação de modelos. Ciência e Tecnologia de Alimentos, Campinas, v. 29, p. 232-240, 2009.

8 FRANCO, C.M.L., DAIUTO, E. R., DEMIATE, I.M.; CARVALHO, L.J.C.B.; LEONEL, M.; CEREDA, M.P.; VILPOUX, O. F.; SARMENTO, S.B.S. Propriedades gerais do amido. Campinas: Fundação Cargill, 2001. 224p.

9 GARCIA, A.; PACHECO-DELAHAYE, E.; TOVAR, J.; PEREZ, E. Caracterizacion fisicoquímica y funcional de lãs harinas de Arracacha (Arracacia xanthorriza) para sopas instantâneas. Ciência y Tecnologia Alimentaria, México, v. 5, p. 384-393, 2007.

10 INSTITUTO ADOLFO LUTZ. Normas analíticas do Instituto Adolfo Lutz: métodos químicos e físicos para análises de alimentos. 4 ed. São Paulo, 2008. 1020 p. (edição digital).

11 IBGE. Instituto Brasileiro de Geografia e Estatistica. Tabela de composição de alimentos: estudo nacional da despesa familiar (ENDEF). 5. ed. Rio de Janeiro, 1999. 137 p.

12 OSBORNE, D.R.; VOOGT, P. The analysis of nutrient in foods. London: Academic Press, 1978. p. 47.

13 PALOU, E.; LÓPEZ-MALO, A.; BARBOSA-CÁNOVAS, G.V.; WELTI-CHANES, J.; SWANSON, B.G. Polyphenoloxidase activity and color of blanched and high hydrostatic pressure treated banana puree. Journal of Food Science, v.64, p.42-45, 1999

14 REIS, F.R. Efeito dos processos de branqueamento e acidificação sobre a cor e a absorção de gorduras de batatas-palha. 2007. 52 f. Dissertação (Mestrado em Tecnologia de Alimentos) - Universidade Federal do Paraná, Curitiba. 2007.

15 RUIZ, W.A.; BONATO, S.R.; ARRIECHE, L.S.; ALVES, F.A. Caracterização da farinha pré-gelatinizada de arroz integral produzida a partir de grãos quebrados. Vetor, Rio Grande, v. 13, p.25-46, 2003.

16 SAEG. Sistema para análises estatísticas. Versão 9.0. Viçosa: Fundação Arthur Bernardes, 2005. (Cd Rom).

17 SABLANI, S. S.; MUJUMDAR, A. S. Drying of potato, sweet potato, and other roots. In: HANDBOOK of industrial drying. $3^{\text {rd }}$ ed. New York: Mujumdar, Taylor \& Francis, 2006. p. 647-646.

18 SARANTÓPOULOS, C.I.G.L.; OLIVEIRA, L. M.; CANAVESI, E. Requesitos de conservação de alimentos em embalagens flexíveis. Campinas: CETEA/ITAL, 2001. 215 p.

19 SIVIERI, K.; OLIVEIRA, M.N. Avaliação da vida-de-prateleira de bebidas lácteas preparadas com "fat replacers" (litesse e dairy-lo). Ciência e Tecnologia de Alimentos, Campinas, v. 22, n. 1; p. 24-31, 2002.

20 WILLARD. M. Potato flour. In: TAUBURT, W. F.; SMITH, O. Processing potato. $3^{\text {rd }}$ ed. Westport: AVI, 1975. p.563-578.

\section{AGRADECIMENTOS}

À Coordenação de Aperfeiçoamento de Pessoal de Nível Superior - CAPES. 